\title{
An AHP-based methodology to rank Critical Success Factors of Executive Information Systems
}

Authors:

Jose L. Salmeron

Associate Professor of MIS

University Pablo de Olavide

email address: jlsalsil@dee.upo.es

Ines Herrero

Assistant Professor of Management

University Pablo de Olavide

email address: ihercha@dee.upo.es 


\title{
An AHP-based methodology to rank Critical Success Factors of Executive Information Systems
}

\begin{abstract}
For academics and practitioners concerned with computer-based Information Systems, one central issue is the study of Critical Success Factors of Information Systems development and implementation. Whereas several Critical Success Factors analyses appear in the literature, most of them do not have any technical background. In this paper we propose the use of the Analytic Hierarchy Process to set Critical Success Factors priorities. Results suggest that technical elements are less critical than information and human factors and that an adequate knowledge of the information requirements of users is the most important Critical Success Factors related with Executive Information Systems.
\end{abstract}

Keywords: Decision support systems, IS design, Process improvement, Project Success Factors

\section{INTRODUCTION}

The study of CSF helps scholars and practitioners to extract from the multidimensional business process the core activities that are essential for business success (Butler and Fitzgerald, 1999). The objective of this study is to rank the Critical Success Factors (CSF) related to Executive Information Systems (EIS) using an Analytical Hierarchy Process. The main strength of this paper is the use of a formal method (a Multicriteria decision making model) for ranking (CSF).

On the other hand, implementing an EIS system is not a risk-free project. In fact, we consider that these systems are very often seen as high-risk projects (Rainer and Watson, 1995; Young and Watson, 1995). Due to the fact that many stakeholders 
Cite as: Salmeron and Herrero (2005). An AHP-based methodology to rank critical success factors of Executive Information Systems. Computer Standards \& Interfaces, 28: 1-12.

doi:10.1016/j.csi.2004.09.002. http://www.sciencedirect.com/science/article/pii/S0920548904001060

(detailed in 3.2.1. section) take part in this process and that they are so closely linked to one another, the chances that something may go wrong are high (Poon and Wagner, 2001; Rainer and Watson, 1995). Therefore it does worth to study the factors that, to a great extent, determine whether the implementation will be successful.

The remainder of this paper is structured as follows: section 2 reviews the research context about EIS and CSF; section 3 is focused on the research model; section 4 presents and analyzes the results; the final section shows the paper's conclusions.

\section{RESEARCH CONTEXT}

\subsection{Executive Information Systems.}

EIS or Executive Support Systems as they are sometimes called, can be defined as computer-based Information Systems that support communications, coordination, planning and control functions of managers and executives in organizations (Bajwa et al., 1998; Elam and Leidner, 1995).

Traditionally EIS has supported only a few top executives. However, EIS can be spread horizontally across and vertically down to other organizational managers (Belcher and Watson, 1993). Although EIS are designed for top executive support, only a few executives make direct use of EIS (Nord and Nord, 1995; Poon and Wagner, 2001; Salmeron, 2002). Currently, EIS is considered by many academics (Volonino et al., 1995; Rai and Bajwa, 1997) as a technology for information delivery for all business and users.

Information Systems for strategic decision support is not an emerging topic. In addition, commercial software packages of EIS are not a growing industry either. However, they are often found as components of Enterprise Resource Planning software (ERP), On-Line Analytical Processing (OLAP), or Data Warehouse applications. Hence, EIS modules are, in a certain way, essential in business. For this reason, we think that EIS is not just a fashionable technology.

\subsection{Critical Success Factors}


The study of Critical Success Factors (CSF) of EIS was developed by Rockart (1979) as a method to enable CEOs to recognize their own information needs so that Information Systems could be built to meet those needs. Rockart defined CSF as:

The limited number of areas in which results, if they are satisfactory, will ensure successful competitive performance for the organization. They are the few key areas where "things must go right" for the business to flourish.

This concept has received a wide acceptance among Information Systems scholars and practitioners (Barrow, 1990; Bergeron and Begin, 1989; Butler and Fitzgerald, 1999; Cottrell and Rapley 1991; Munro and Wheeler, 1980; Poon and Wagner, 2001; Rainer and Watson, 1995; Rockart and DeLong, 1988; Shank et al., 1985). CSF is an interpretative method and, as such, it may be employed for research on the Information Systems development process (Butler and Fitzgerald, 1999).

Experts (Glass 1999; Procaccino et al., 2002) suggest a deep divergence between managers/users and the members of the development team regarding the success of the different Information Systems. Whereas managers/users focus their attention on budget, dates and business objectives, the members of the development team mainly pay attention to Information Systems development. In this work we analyze the different views of managers and users.

Numerous scientific publications address the issue of CSF in the field of Information Systems field (Bergeron and Begin, 1989; Butler and Fitzgerald, 1999; Cottrell and Rapley, 1991; Poon and Wagner, 2001; Shank et al., 1985) as well as in other fields (Slevin and Pinto, 1987; Bashein et al., 1994; Munro et al., 1980). According to Butler ant Fitzgerald (1999), who made summary of research on CSF in the IS discipline, little efforts have been done for CSF ranking. Some authors, such as Poon and Wagner (2001), analysed some aspects of CSF just by the use of personal interviews whereas others, such as Nord and Nord (1995), carried out a comparative analysis of EIS. However, none of them used a formal methodology. Therefore, we think that a formal method to rank CSF of EIS is an useful endeavour.

\section{RESEARCH MODEL}




\subsection{Ranking approach}

Several methods can be used to classify different EIS. Multivariate techniques could have been used. However they do not incorporate the preference structure of the decision maker. Similarly different efficiency techniques could have been used. These techniques are used to measure the performance efficiency of different Decision Making Units (DMUs). By a DMU we mean a unit whose performance we are interested in evaluating. DMUs can be of very different nature, like a computer system, a productive unit, a school, etc. This efficiency is measured according to the amount of resources, or inputs, involved in the process and the amount of outputs produced.

The efficiency of a given unit is higher than the efficiency of another if it can get more outputs out of the same or less amount of inputs or if it can get the same amount of outputs out of a small amount of inputs. For example, the Data Envelopment Analysis technique (or DEA) measures the efficiency rate by the ratio of a weighted sum of outputs over a weighted sum of inputs. The weights can take any value. In DEA, this value is the best set of weights that would make the unit as efficient as possible. Therefore, the weight or the importance given to each criteria is different for each unit. The weights given to each of the criteria may take any value and none of them can be considered more important than any other. However, these methods are more appropriate when the decision maker has no clear preferences over the different attributes, or when the interest is focused on getting the EIS that performs better independent of personal preferences. On the contrary, the Analytic Hierarchy Process (AHP) allows managers to express their individual preferences. Therefore, each EIS can be evaluated using this set of preferences to get a score and this can provide an EIS ranking for each decision maker. This allows each manager to choose (according to his preferences) the EIS that is more appropriate. If it is desired to obtain the EIS that satisfies the interests of the majority of all managers then there exist several methods to get a set of global preferences either by simply averaging the individual scores or by producing a weight according to the importance of the decision maker (the different techniques of aggregation can be seen in Mardle et al., 2003).

The Analytic Hierarchy Process (AHP) was developed by Saaty $(1977,1980)$. It is a powerful and flexible decision-making process to set priorities among different 
Cite as: Salmeron and Herrero (2005). An AHP-based methodology to rank critical success factors of Executive Information Systems. Computer Standards \& Interfaces, 28: 1 -12.

attributes. AHP is a method that uses a hierarchic structure to present a complex decision problem by decomposing it into several smaller subproblems. AHP has been widely used to reflect the importance, or weights, of the factors associated to priorities (see Zahedi 1986).

AHP has been widely applied in the field of Information Systems (Chikara and Takahashi, 1997; Khoo et al., 2002; Lee, 1993; Lu et al., 2001; Min, 1992; Mitta, 1993; Muralidhar et al., 1990; Schniederjans and Wilson, 1991; Yang and Huang, 2000; Yau and Davis, 1993; Zahedi, 1985). However, little has been done to design a formal method for the assessment of Critical Success Factors. We propose AHP method for it.

The AHP method encompasses three basic steps: firstly the decision problem has to be broken down into a hierarchy of interrelated elements; secondly, the data has to be collected by pairwise comparisons of former elements and the attributes' weights in each level have to be computed using the eigenvalue method; finally the categories' weights have to be calculated.

\subsection{Constructing the hierarchy}

In order to study the Critical Success Factors related with Executive Information Systems, we have established three categories: human resources, information and technology and system interaction (Figure 1).

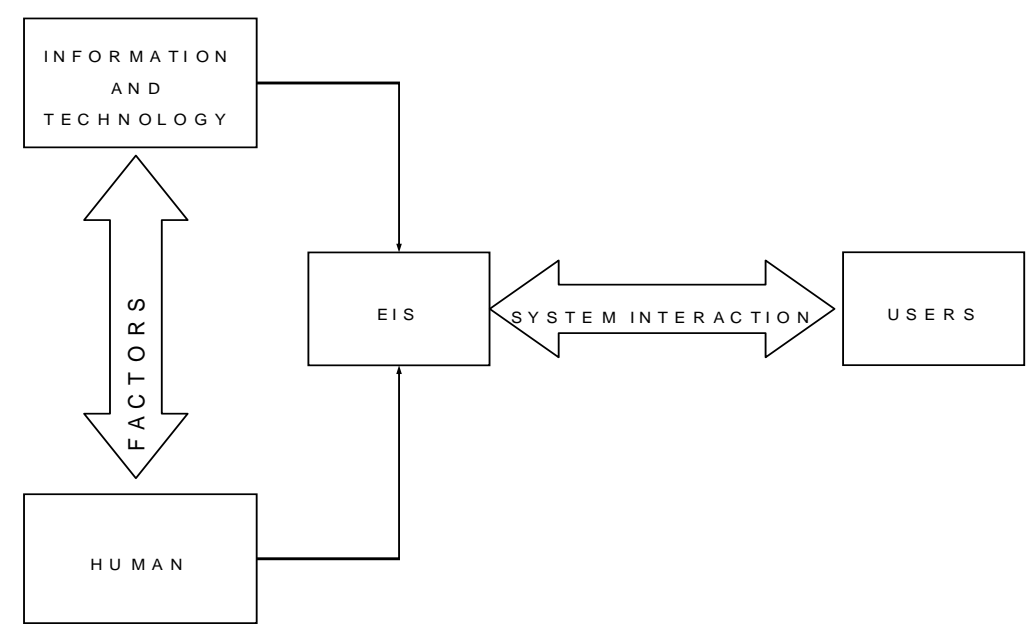

Figure 1. EIS model 
The determination of the degree of importance associated to the CSF can be resolved by decomposing it into subproblems within a hierarchy structure. The highest level with only one element is the goal to reach, and the elements in the lowest level are the factors. Elements in the middle levels are the criteria or categories for evaluating those factors. In this work the hierarchy of all criteria and factors were classified into three levels as depicted in Figure 2.

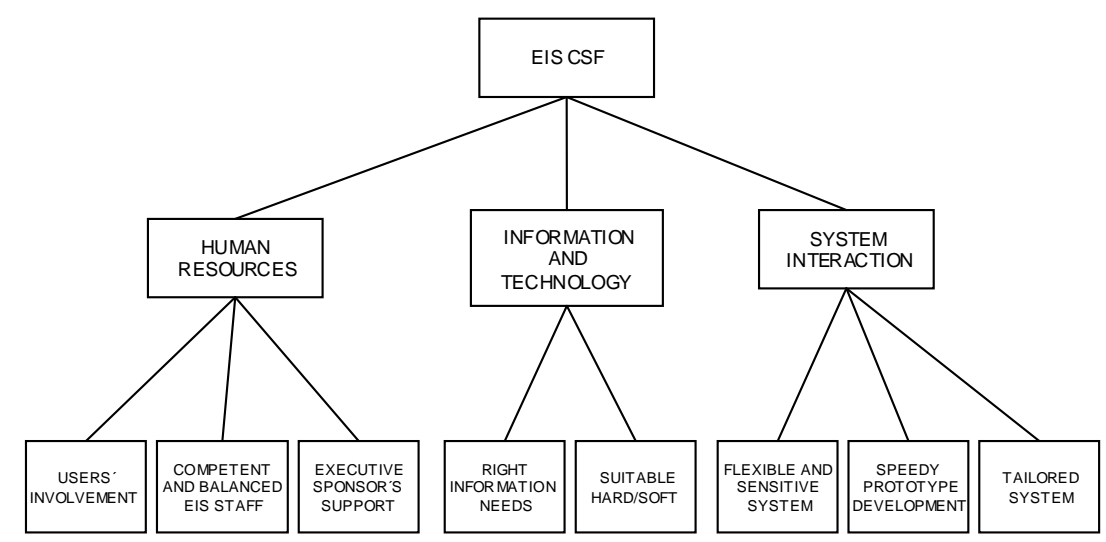

Figure 2. Critical Success Factors hierarchy model

At the highest level (level 1) of the hierarchy are CSFs. It is possible to classify the CSFs into three categories: information and technology, human resources and system interaction. This taxonomy constitutes the second level and it is based in the EIS model (Figure 1). The third level shows the specific CSFs within each category.

In this paper we do not assess more complex concepts, such as right information needs or users' interest because it is difficult to get a reliable measure of this kind of attributes just by interviewing. Our goal is to obtain the users' perceptions about the importance of CSF in order to establish a rank among them. It is a valuable effort, since IS users and IS experts have significantly different perceptions on IS success (Jiang et al., 2002).

\subsubsection{Human resources}

This category includes the following CSFs: users' involvement, existence of executive sponsor support and the need for a competent and balanced EIS staff. 
In the following literature (Barki and Hartwick, 1989; Hwang and Thorn, 1999; Kappelman and McLean, 1991; Young and Watson, 1995) user's involvement is defined as a mental or psychological state of users toward the system and its development process. It is generally accepted that Information Systems users' involvement in the application design is important and necessary (Barki and Hartwick, 1994; Franz and Robey, 1986; Hunton and Beeler, 1997; Hwang and Thorn, 1999; Ives et al., 1983; Ives and Olson 1984; Jiang et al. 2000; Lin and Shao, 2000; Vandenbosch and Higgins, 1995), as the lack of their involvement may represent a serious problem for the system (Walstrom and Wilson, 1997). This is especially important in an EIS development project, because more and more users' involvement is required for an Information System that faces higher-level, less-structured problems (Edstrom, 1977; Rainer and Watson, 1995). EIS often fail because of their inability to meet the expectations of users (Szajna and Scamell, 1993). User's involvement in EIS design brings about realistic expectations of system capabilities (Gibson, 1977) and decreases the risk of failure. Typically, users' involvement is higher in open rather than in packaged software (Carmel and Sawyer, 1998; Keil and Carmel, 1995; Sawyer, 2000). In addition, working on EIS design increases users' understanding and acceptance, improving requirements determination and reducing problems. User's involvement is also believed to increase user's acceptance of the system with a more realistic expectation about system capabilities (Gibson, 1977; Lin and Shao, 2000) and greater commitment from users (Markus, 1983).

The following CSF in this category is the need for a competent and balanced EIS staff. Suitable human resources are required for developing EIS. Typical responsibilities include the selection of hardware and software, the identification of information requirements, the access of information, the design of screens and facilitating some training (Watson et al., 1996). It is possible to distinguish among several roles (Salmeron, 2002), such as: executive sponsor, operating sponsor (Bird, 1991) and EIS staff.

The executive sponsor is the executive who promotes the system and whose mission is not focused on the daily activity of development and implementation process, but on supporting the EIS with his/her authority and influence over the rest of 
Cite as: Salmeron and Herrero (2005). An AHP-based methodology to rank critical success factors of Executive Information Systems. Computer Standards \& Interfaces, 28: 1-12.

doi:10.1016/j.csi.2004.09.002. http://www.sciencedirect.com/science/article/pii/S0920548904001060

the executives. Executive sponsor support is critical for EIS success (Procaccino et al., 2002).

The operating sponsor is the most responsible person for the development and the implementation process. The role of the EIS staff is the development of EIS and its implementation. This staff must be composed of expert personnel, both in technical devices and in the activity of the organization. Its multidisciplinary composition is so important that the existence of a competent and balanced development team is one of the most basic factors for success (Barrow, 1990; Bird 1991; Nord and Nord, 1995). In general, executives support people's needs, strong interpersonal skills and a broad range of technical and business knowledge (Jiang, et al., 1999; Martinsons and Cheung, 2001).

\subsubsection{Information and Technology}

This category includes the following CSFs: suitable hard-soft and right information needs.

EIS must provide a broad variety of capabilities. To be effective in supporting executives, an EIS needs suitable hard/soft resources (Young and Watson, 1995). Regarding software, there are many ways of designing Executive Information Systems, depending on the philosophy and approach adopted. The frequently encountered design question is whether one should make use of existing systems to build EIS. The first Executive Information Systems were developed in-house based on existing software (Belcher and Watson, 1993; Houdeshel and Watson, 1987; Moynihan, 1993), for example Conoco (Belcher and Watson, 1993), Lockheed-Georgia (Volonino and Watson, 1990) and NASA (Moynihan, 1993). In the mid 1980s, commercial EIS software was devised. Client/server EIS software emerged later.

Developers can build EIS systems using programming languages, Database Management Systems (DBMS) or a blend of the two. The main benefit when the software chosen is already in the company is its low cost. On the other hand the main disadvantage is the long time required for its development. Another option is the use of specific EIS tools. These tools have several benefits: several graphical user's interfaces, the existence of support for speed design, their easy maintenance, the 
Cite as: Salmeron and Herrero (2005). An AHP-based methodology to rank critical success factors of Executive Information Systems. Computer Standards \& Interfaces, 28: 1-12.

doi:10.1016/j.csi.2004.09.002. http://www.sciencedirect.com/science/article/pii/S0920548904001060

possibility to import data from others databases, the existence of templates and interfaces for other tools and information services. Although it is possible to develop an EIS by using general purpose tools, the advantages offered by the use of specific tools for the development of EIS discourage users from choosing the former alternative. Nowadays, developers can use tools that are included in ERP for building an EIS. For instance, SAP R/3 business intelligence offers reporting, analysis, information delivery and other EIS capabilities.

On the other hand, the literature (Bird, 1991; Frolick and Robichaux, 1995; Glass, 1998; Paller and Laska, 1990; Poon and Wagner, 2001; Vandenbosch and Huff, 1997) confirms that right information needs is an EIS CSF and a critical phase in any Information Systems development (Browne and Ramesh, 2002). Eliciting requirements is one of the most complicated tasks in developing systems, and getting a correct requirement set is challenging because it is hard to express the behaviour of a machine in human language (Tackett and Doren, 1998).

Clearly, an EIS is, in basic terms, an information delivery system. If information is unsuitable, the system will also be unsuitable. The ability to provide access to reliable information from both internal and external sources is a major issue in EIS development (Poon and Wagner, 2001). In addition, executive information needs are dynamic in most industries. Alterations in the organization, in business or in industry usually require changes in information needs. Therefore, it implies the need for changes in EIS.

\subsubsection{System interaction}

The system interaction category includes the following CSFs: a flexible and sensitive system, a speedy prototype development and a tailored system.

EIS must be flexible enough to be able to get adapted to changes in the types of problems and the needs of information (Rockart, 1979). Otherwise, it would soon become a useless tool that would deal with outdated problems and would not contribute to decision making. Flexibility and sensitivity are essential characteristics in Information Systems for strategic support (Houdeshel and Watson, 1987; Rockart and 
Cite as: Salmeron and Herrero (2005). An AHP-based methodology to rank critical success factors of Executive Information Systems. Computer Standards \& Interfaces, 28: 1 -12.

doi:10.1016/j.csi.2004.09.002. http://www.sciencedirect.com/science/article/pii/S0920548904001060

De Long, 1988) and inherent to EIS concept (Rockart and Treacy 1982; Watson et al. 1997; Young and Watson 1995).

On the other hand, users who are not familiar with prototyping often have unrealistic expectations (Baskerville and Stage, 1996; Hardgrave et al., 1999). These expectations may lead to disappointment regarding the final system. Speedy development of a prototype encourages the users' motivation (Guimaraes and Saraph, 1991), because it interacts between user and system as soon as possible. This CSF is strongly related to users' involvement. However, it is referred to the collaboration in the whole development process and prototyping is focus to system interaction in this context.

The following CSF in this category is the existence of a tailored system. EIS are tools designed for the manager's direct use (Nord and Nord 1995; Young and Watson 1995). The manager's direct interaction with the information provided by the EIS may encourage him to take new lines of action. This will not be the case if EIS are used by the staff instead of being used by managers (Leidner and Elam, 1994; Tang et al., 1998). For that reason, it is necessary to design the system specially for those particular users.

Once we have chosen the main attributes of EIS and have defined a hierarchy among them, the following step within the AHP method is focused on collecting data by pairwise comparisons of the different criteria. Making pairwise comparisons seems to be a more reliable way of obtaining the actual weights than obtaining them directly as it is generally easier to evaluate the relative weights of each attribute with respect to the others.

\subsubsection{Pairwise comparisons and computation of the factors' weights}

Three stages describe this phase (Yang and Huang, 2000): Firstly the computation of the different weights by asking the importance of each attribute with respect to each of the others through pairwise comparisons. The second step consists on the computation of a vector of priorities and the third step is to measure the consistency of the judgements of the answers. 
In the first step the attributes of each EIS are compared in terms of their importance within a given category. The attributes of all categories have to be compared (within their own category). Several ways of making the comparisons exist and the number of them depends on the trust the decision maker puts on the consistency of the human group being interviewed.

The most common one requires from the interviewed group to provide a rate, $w_{\mathrm{AB}}$, regarding the importance of an attribute, $\mathrm{A}$, in comparison to the importance of another attribute of the same category, $\mathrm{B}$. Then, the reciprocal comparison, the rate of the importance of attribute $B$ over $A$, is deduced from the previous (and is given by $\left.1 / w_{\mathrm{AB}}\right)$, This procedure reduces the number of comparisons for the interview to $n(n-$ $1) / 2$, where $n$ is the number of attributes in that category. This is the procedure we have used in this paper. By using this procedure, there are no symmetric inconsistencies (the importance of $B$ over $A$ will always be consistent with the importance of $A$ over $B$ ). However, the transitive property may not be hold (i.e., the degree of importance of $A$ over $B$ does not have to be consistent with the importance of A over $\mathrm{C}$ and $\mathrm{C}$ over $\mathrm{B}$ ). Therefore, the possibility of potential inconsistencies has to be analysed (and it will be done in step 3).

We have used the widely accepted 9-point scale which is the original scale suggested by Saaty in 1977. The meaning of each of the values of the scale is shown in Table 1. The inverse but analogous scale is used for $B$ being preferred to $A$. That is, if, for example, $B$ is moderately to strongly prefer over $A$ then we will rate the importance of $A$ over $B$ as $1 / 4$. Note that this implies that zero cannot be included in the scale for pairwise comparisons ${ }^{1}$.

Table 1

Pairwise comparison scale for AHP preferences

\begin{tabular}{cl}
\hline Numerical rating & \multicolumn{1}{c}{ Verbal judgements of preferences } \\
\hline 1 & A is equally preferred to $B$ \\
2 & A is equally to moderately preferred over $B$ \\
\hline
\end{tabular}

Therefore, 1 is the middle of the scale, meaning equal preference of the two attributes being compared. 
Cite as: Salmeron and Herrero (2005). An AHP-based methodology to rank critical success factors of Executive Information Systems. Computer Standards \& Interfaces, 28: 1 -12.

doi:10.1016/j.csi.2004.09.002. http://www.sciencedirect.com/science/article/pii/S0920548904001060

\begin{tabular}{ll}
\hline 3 & A is moderately preferred over B \\
4 & A is moderately to strongly preferred over B \\
5 & A is strongly preferred over B \\
6 & A is strongly to very strongly preferred over B \\
7 & A is very strongly preferred over B \\
8 & A is very strongly to extremely preferred over B \\
9 & A is extremely preferred over B \\
\hline
\end{tabular}

The numerical values representing the judgements of the pairwise comparisons are arranged in the upper triangle of the square matrix. For example, $a_{i j}$ represents how much criteria $i$ is preferred over criteria $j$. This means that:

$$
a_{i j}=w_{i} / w_{j}
$$

The elements in the main diagonal of $A$ are all equal to 1 and the elements of the down triangle are the inverse of the elements in the upper triangle (i.e., $a_{j i}=1 / a_{i j}=$ $\left.1 /\left(w_{i} / w_{j}\right)=w_{j} / w_{i}\right)$. Each of its elements, $a_{i j}$, is the ratio of the absolute weight relative to the importance of criteria $i$ over the absolute weight relative to the importance of criteria $j$. Note that the matrix is provided directly by the results of the questionnaire

Therefore the matrix becomes:

$$
A=\left(a_{i j}\right),(i, j=1, \ldots, n) ; \quad A=\left(\begin{array}{ccc}
1 & \ldots & a_{i j} \\
\ldots & 1 & \ldots \\
1 / a_{i j} & \ldots & 1
\end{array}\right)
$$

That is:

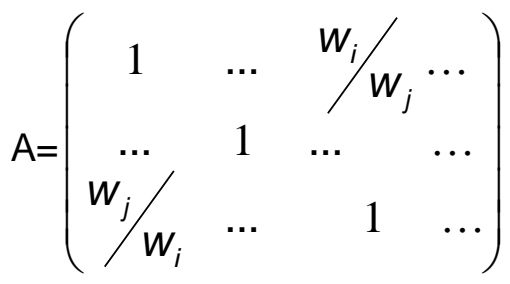


Cite as: Salmeron and Herrero (2005). An AHP-based methodology to rank critical success factors of Executive Information Systems. Computer Standards \& Interfaces, 28: 1-12.

doi:10.1016/j.csi.2004.09.002. http://www.sciencedirect.com/science/article/pii/S0920548904001060

Note that the elements of this matrix reflect the importance of each attribute with respect to another. However, we are interested in knowing the value of the weight of each attribute in itself (the vector of priorities), not the weights when compared to the other attributes. This is done in the next step of the analysis.

Note also that this matrix verifies that:

$$
A w=\mathrm{n} \bullet \mathrm{w}
$$

Where $w$ is the vector of the actual absolute weights and $n$ is the number of criteria. We need to use the above equality to get the weights of each attribute. It has been proved that $n$ is the largest eigenvalue of matrix A (Saaty, 1977) and that the vector of weights we are looking for is the eigenvalue associated to this value (for the mathematical demonstration see Saaty, 1977).

These weights are what are called the local weights, i.e., the weights within the category they belong to. If there is an upper category, then the absolute weights are given by multiplying the weight of the attribute above by the local weights. By doing this, we can get a normalised set of weights for all the attributes in the lower category.

Hence, we need to calculate the eigenvalues of this matrix, consider the largest one and calculate the associated eigenvector, which would be the relative weights we are looking for. The calculation of eigenvalues and eigenvectors is a simple and common procedure (which will not be presented here) in mathematics. This can be computed using any mathematical software. We used Expert choice (EC) software for computing the categories' weights. EC is an AHP-based multi-objective decision support tool. It is designed for the analysis, synthesis and validation of complex individual or group decisions.

These weights must verify (Saaty, 1977):

$$
A w=\lambda_{\max } \bullet w
$$


Where $\lambda_{\max }$ is the largest eigenvalue of $A$ and $w$ is the eigenvector associated to that eigenvalue. The value $\lambda_{\max }=n$ should always be the largest eigenvalue of $A$. However, inconsistencies in the answers of the people interviewed may lead to a different value. The closer to $n$, the greater the consistency of the answer.

A normalised consistency ratio (CR), based on the divergence of the largest eigenvalue to $n$ is commonly used in the literature (see, for example, Zahedi, 1986). The closer the CR is to zero the greater the consistency. As was stated before, the equality $a_{i j}=1 / a_{i i}$ holds by construction. The answers are consistent if the equality $a_{i j} \cdot$ $a_{j k}=a_{i k}$ holds for all attributes. That is, if the transitive property holds (the preference of $A$ over $B$ is equal to the preference of $A$ over $C$ times the preference of $C$ over $B$ ). If this equality does not held for a given decision maker, it means that the decision maker is not consistent in his statements and the interview should be done again.

In practice, the weights are considered valid if both terms of the equality do not differ much; otherwise the answer of the decision maker under analysis is either eliminated from the dataset or the questions regarding the attributes involved in the equality have to be redone. The maximum accepted upper value for the consistency ratio is 0.1 (Zahedi, 1986). This measure of consistency can be used to evaluate the consistency of decision makers as well as the consistency of all the hierarchy (Yang and Huang, 2000) or even or the possibility that the matrix was filled at random.

\section{FINDINGS}

The respondents are eighteen EIS users of leading companies. The composition of the respondents is important. Multiple choices were contemplated. The main selection criteria considered was recognized knowledge in research topic, absence of conflicts of interest, and geographic diversity. All conditions were respected. In addition, respondents were not chosen just because they are easily accessible.

The results from the three pairwise comparison matrices are detailed in Table 2. Table 3 shows the three normalized matrices associated to those in Table 2. Table 4 summarizes the local weights for each category and Table 5 shows the global weights- 
Cite as: Salmeron and Herrero (2005). An AHP-based methodology to rank critical success factors of Executive Information Systems. Computer Standards \& Interfaces, 28: 1 -12.

doi:10.1016/j.csi.2004.09.002. http://www.sciencedirect.com/science/article/pii/S0920548904001060

based CSF ranking. As all experts' opinions were considered to be of the same importance, we used the geometric mean as the aggregation method for the calculation of the average local and global weights. In table 2 have also been presented the consistency ratio associated to the comparison matrices. They are all far below the maximum value, 0.1, suggested by some authors (see Zahedi, 1986).

Table 2

Pairwise comparison matrices

\begin{tabular}{l|ccc}
\hline \multicolumn{1}{c|}{$\begin{array}{c}\text { Human resources } \\
\text { CR }=0.01\end{array}$} & Users' interest & $\begin{array}{c}\text { Competent and balanced } \\
\text { EIS staff }\end{array}$ & $\begin{array}{c}\text { Executive sponsor's } \\
\text { support }\end{array}$ \\
\hline $\begin{array}{l}\text { Users' interest } \\
\begin{array}{l}\text { Competent and balanced EIS } \\
\text { staff }\end{array}\end{array}$ & 1 & 3 & 2 \\
Executive sponsor's support & $1 / 3$ & 2 & $1 / 2$ \\
\hline \multicolumn{2}{c}{ Info - Tech resources } \\
CR = 0.00
\end{tabular}

Table 3

Normalized matrices 
Cite as: Salmeron and Herrero (2005). An AHP-based methodology to rank critical success factors of Executive Information Systems. Computer Standards \& Interfaces, 28: 1 -12.

doi:10.1016/j.csi.2004.09.002. http://www.sciencedirect.com/science/article/pii/S0920548904001060

\begin{tabular}{|c|c|c|c|c|}
\hline Human resources & Users' interest & $\begin{array}{l}\text { Competent and } \\
\text { balanced EIS staff }\end{array}$ & $\begin{array}{l}\text { Executive sponsor's } \\
\text { support }\end{array}$ & Local Weights \\
\hline Users' interest & 0,545 & 0,500 & 0,571 & 0,540 \\
\hline $\begin{array}{l}\text { Competent and } \\
\text { balanced EIS staff }\end{array}$ & 0,182 & 0,167 & 0,143 & 0,163 \\
\hline $\begin{array}{l}\text { Executive sponsor's } \\
\text { support }\end{array}$ & 0,273 & 0,333 & 0,286 & 0,297 \\
\hline Info - Tech resources & \multicolumn{2}{|l|}{ Right info needs } & Suitable Hard / Soft & Local Weights \\
\hline Right info needs & 0,889 & \multicolumn{2}{|r|}{0,889} & 0,889 \\
\hline Suitable Hard/Soft & 0,111 & \multicolumn{2}{|r|}{0,111} & 0,111 \\
\hline System interaction & $\begin{array}{c}\text { Flexible and } \\
\text { sensitive system }\end{array}$ & $\begin{array}{l}\text { Speedy development } \\
\text { of a prototype }\end{array}$ & Tailored system & Local Weights \\
\hline $\begin{array}{l}\text { Flexible and sensitive } \\
\text { system }\end{array}$ & 0,300 & 0,375 & 0,286 & 0,320 \\
\hline $\begin{array}{l}\text { Speedy development } \\
\text { of a prototype }\end{array}$ & 0,100 & 0,125 & 0,143 & 0,122 \\
\hline Tailored system & 0,600 & 0,500 & 0,571 & 0,556 \\
\hline
\end{tabular}

Table 4

Summary of local weights

\begin{tabular}{clc}
\hline \multicolumn{1}{c}{ Categories } & \multicolumn{1}{c}{ CSFs } & Local weights \\
\hline \multirow{3}{*}{ Human resources } & Users' interest & $0.540(1)$ \\
& Competent and balanced EIS staff & $0.163(3)$ \\
& Executive sponsor's support & $0.297(2)$ \\
\hline \multirow{2}{*}{ Info and Tech resources } & Right info needs & $0.889(1)$ \\
& Suitable Hard / Soft & $0.111(2)$ \\
\hline \multirow{3}{*}{ System interaction } & Flexible and sensitive system & $0.320(2)$ \\
& Speedy development of a prototype & $0.122(3)$ \\
& Tailored system & $0.558(1)$ \\
\hline
\end{tabular}

As shown in Table 4, users' interest was the most critical factor with a local weight of 0.540 in the Human resources category. It was about two to three times greater than 
Cite as: Salmeron and Herrero (2005). An AHP-based methodology to rank critical success factors of Executive Information Systems. Computer Standards \& Interfaces, 28: 1-12.

doi:10.1016/j.csi.2004.09.002. http://www.sciencedirect.com/science/article/pii/S0920548904001060

that of the executive sponsor's support (0.297), and the competent and balanced EIS staff $(0.163)$.

Right information needs was the most critical factor with a local weight of 0.889 in the Information and Technology resources category. It was about eight times greater than that of the suitable hard / soft $(0.111)$.

Tailored system was the most critical factor with a local weight of 0.558 in the System interaction category. It was about two to five times greater than that of the flexible and sensitive system (0.320), and the speedy development of a prototype (0.122).

Table 5

Category ranking with global weights

\begin{tabular}{lc}
\hline \multicolumn{1}{c}{ Category } & Global weights \\
\hline Info and Tech resources & 0.598 \\
Human resources & 0.283 \\
System interaction & 0.119 \\
\hline
\end{tabular}

As shown in Table 5, Information and Technology resources category is the most valued in the second hierarchy level. It was about two to five times greater than that of the Human resources category (0.283), and system interaction category (0.119).

Table 6

CSF ranking with global weights

\begin{tabular}{llcc}
\hline & \multicolumn{1}{c}{ CSFs } & Global weights & Category \\
\hline 1. & Right info needs & 0.532 & Info-Tech resources \\
2. & Users' interest & 0.153 & Human resources \\
\hline
\end{tabular}


Cite as: Salmeron and Herrero (2005). An AHP-based methodology to rank critical success factors of Executive Information Systems. Computer Standards \& Interfaces, 28: 1-12.

doi:10.1016/j.csi.2004.09.002. http://www.sciencedirect.com/science/article/pii/S0920548904001060

\begin{tabular}{clcc}
\hline 3. & Executive sponsor's support & 0.084 & Human resources \\
4. & Tailored system & 0.067 & System interaction \\
5. Suitable Hard / Soft & 0.066 & Info-Tech resources \\
$6 . \quad$ Competent and balanced EIS staff & 0.046 & Human resources \\
7. Flexible and sensitive system & 0.038 & System interaction \\
8. Speedy development of a prototype & 0.014 & System interaction \\
\hline Overall CR $=0.04$ & &
\end{tabular}

Table 6 shows the global weights-based CSF ranking. They have been calculated by multiplying the local weights of each CSF by the global weight of each category. By doing this, each local CSF is balanced by the importance of the category to which it belongs. Right information needs was the most critical factor with a global weight of 0.532. It was from three to thirty-eight times greater than the rest. The second CSF is user's interest (0.153) and the third is executive sponsor's support (0.084).

\section{DISCUSSION AND CONCLUSIONS}

The main strengths of this paper are two-folds: it provides a method for ranking Critical Success Factors and it also allows a consistency measure of results. In this paper we proposed the use of the Analytic Hierarchy Process to rank different Critical Success Factors related with Executive Information Systems. The technique seems to perform better than results based purely on the experts' assignation of the absolute priorities of each criteria (Zahedi, 1986) or than results based just on qualitative analysis. Note also that by using this technique, the level of importance of each attribute is compared to the others. According to experts (Zahedi, 1986) the fact of seeing attributes relative to others (i.e. making comparisons) seems to be an easier way to calibrate their importance. Furthermore, by using AHP, some inconsistencies may arise, giving place for reconsideration of judgements and unveiling some unclear thinking regarding the assessments of some of the attributes. However, this technique has not traditionally been applied for the analysis of Critical Success Factors related with Executive Information Systems.

The results not mean that any CSF is unimportant. It means what are the respondents' perceptions about the importance of them. This is a main issue, since it is possible to manage the development process with more information about the expectations of final users. 
Incorporating the analysis of AHP evidences, the study verified that the technical factors (suitable hard / soft, flexible and sensitive system and speedy development of a prototype) get lower values than information and soft factors (right information needs, user's interest, executive sponsor's support) probably because the respondents are users themselves. They are not familiarized with the development process. This work is focused on the users' point of view. This is an useful approach since users' satisfaction is more critical in Executive Information Systems than others systems. Users are interested in Executive Information Systems getting adapted to them and to include the right information.

The most expected find is that, in the overall opinion, right information needs seems to be, by far, the highest priority criteria. The weight associated to this factor is higher than the priority of all the rest together. In general terms, this study argues that technical elements are less critical than information and human factors. So, this paper confirms the literature. At the same time, the technique proposed is validated.

The weights for the different criteria obtained by using the Analytic Hierarchy Process method can be subsequently used to rank different computer-based Executive Information Systems. This can be done using different techniques. For example, an efficiency score for each Executive Information Systems can be calculated simply by calculating the weighted sum of each attribute (using the weights given by the Analytic Hierarchy Process analysis). The ranking can also be obtained using the weights resulting from an Analytic Hierarchy Process analysis in a goal programming model; this is done by minimising the maximum deviation of the interest of each manager to the overall interests (for a more detailed explanation see for example Bryson, 1995). The Critical Success Factors priority scores will be used to weight the specific value of each factor for each different Executive Information Systems.

\section{REFERENCES}

Bajwa, D.S., Rai, A., Brennan, I. "Key antecedents of Executive Information Systems success: a path analytic approach", Decision Support Systems (22:1) 1998, pp. 31-43. 
Cite as: Salmeron and Herrero (2005). An AHP-based methodology to rank critical success factors of Executive Information Systems. Computer Standards \& Interfaces, 28: 1-12.

Barki, H. and Hartwick, J. "Rethinking the concept of user involvement", MIS Quarterly (13:1) 1989, pp. 53-63.

Barki, H., Hartwick, J. "Measuring user participation, user involvement end user attitude", MIS Quarterly (18:1) 1994, pp. 59-79.

Barrow, C., "Implementing an Executive Information Systems: Seven steps for success", Journal of information systems management 7 1990, pp. 41-52.

Baskerville, R.L. and Stage, J. "Controlling prototype development throught risk analysis", MIS Quarterly 20(4) 1996, pp. 481-504.

Bashein, B.J.; Markus, M.L. and Riley, P. 1994. "Preconditions for BPR Success and How to Prevent Failures," Information Systems Management, Spring, pp. 7-13.

Belcher, L.W., Watson, H.J. “Assessing the value of Conoco's EIS”, MIS Quarterly 17 (3) 1993, pp. 239-254.

Bergeron, F. and Begin, C. 1989. "The use of critical success factors in evaluation of information systems: a case study", Journal of Management Information Systems 5 (4), pp. 111-124.

Bird, J. Executive Information Systems Management Handbook. NCC Blackwell, Manchester, 1991.

Browne, G.J. and Ramesh, V. "Improving information requirements determination: a cognitive perspective", Information \& Management (39:8) 2002, pp. 625-645.

Butler, T. and Fitzgerald, B. 1999. "Unpacking the systems development process: An empirical application of the CSF concept in a research context" Journal of Strategic Information Systems (8), pp. 351-371.

Bryson, N. 1995. A goal programming method for generating priority vectors. Operational Research Society 46(5): 641-648.

Carmel, E. and Sawyer, S. "Package software development teams: what makes them different?", Information Technology \& People (11:1) 1998, pp. 7-19. 
Cite as: Salmeron and Herrero (2005). An AHP-based methodology to rank critical success factors of Executive Information Systems. Computer Standards \& Interfaces, 28: 1 -12.

Chikara, T. and Takahashi, T. 1997. Research of measuring the customer satisfaction for information systems, Computers \& Industrial Engineering, 33(3-4), pp. 639642.

Cottrell, N. and Rapley, K. 1991 "Factors critical to the success of executive information systems in British Airways", European Journal of Information Systems 1(1), 6577.

Edstrom, A. "User influence and the success of MIS project: a contingency approach", Human relations 30 1997, pp. 595-607.

Elam, J.J., Leidner, D.G. "EIS adoption, use and impact: The executive perspective", Decision Support Systems, (14:2) 1995, pp. 89-103.

Finnie, G.R.; Wittig G.E. and Petkov, D.I. (1993), Prioritizing Software Development Productivity Factors Using the Analytic Hierarchy Process, Journal of Systems and Software 22 (2), pp. 129-139.

Franz, C.R. and Robey, D. 1986. "Organizational context, user involvement, and the usefulness of information systems", Decision Sciences (17), pp. 329-353.

Frolick, M.N., Robichaux, B.P. "EIS information requirements determination: Using a group support systems to enhance the strategic business objectives method", Decision Support Systems (14:2), 1995, pp. 157-170.

Gibson, H.L. "Determining user involvement”, Journal of Systems Management (28:8) 1977, pp. 20-22.

Glass, R.L. Software Runaways. Prentice-Hall, New Jersey, 1998.

Glass, R.L. "Evolving a new theory of project success", Communications of the ACM (41:12) 1999, p. 17

Guimaraes, T., and Saraph, J.V. "The role of prototyping in Executive Decision Systems", Information \& Management (21:5) 1991, pp. 257-268. 
Cite as: Salmeron and Herrero (2005). An AHP-based methodology to rank critical success factors of Executive Information Systems. Computer Standards \& Interfaces, 28: 1-12.

Hardgrave, B.C.; Wilson, R.L. and Eastman, K. "Toward a contingency model for selecting and Information System Prototyping Strategy", Journal of Management Information Systems, (16:2) 1999, pp. 113-136.

Houdeshel, G., and Watson, H.J. "The management information and decision support (MIDS) system at Lockheed-Georgia", MIS Quarterly (11:1) 1987, pp. 127-131.

Hunton, J.E., and Beeler, J.D., "Effects of user participation in systems development: A longitudinal field experiment”, MIS Quarterly (21:4) 1997, pp. 359-388.

Hwang, M.I. and Thorn, R.G. "The effect of user engagement on system success: A meta-analytical integration of research findings", Information \& Management (35) 1999, pp. 229-236.

Ives, B. and Olson, M.H. "User involvement and MIS success: a review of research", Management Science (30:5) 1984, pp. 586-603.

Ives, B.;Olson, M.H., and Baroudi, J.J. "The measurement of user information satisfaction", Communications of the ACM (26:10) 1983, pp. 586-603.

Jiang, J.J.; Klein, G.; Balloun, J.L. and Crampton, S.M. 1999. "System analysts' orientations and perceptions of system failure", Information and Software Technology 41(2), pp. 101-106.

Jiang, J.J.; Muhanna, W.A. and Klein, G. 2000. "User resistance and strategies for promoting acceptance across system types", Information \& Management 37 (1), pp. 25-36.

Jiang, J.J. Klein, G. and Discenza, R. 2002. Perception differences of software success: provider and user views of system metrics. Journal of Systems and Software 63, pp. 17-27

Kappelman, L. and McLean, E. 1991. "The Respective Roles of Users Participation and User Involvement in the Information System Implementation Success", ICIS Conference Proceedings, pp. 339-349. 
Cite as: Salmeron and Herrero (2005). An AHP-based methodology to rank critical success factors of Executive Information Systems. Computer Standards \& Interfaces, 28: 1 -12.

Keil, M. and Carmel, E. 1995. "Customer-developer links in software development", Communications of the ACM 38(5), pp. 33-44.

Khoo, L.P.; Chen, C. and Yan, W. 2002. An investigation on a prototype customeroriented information system for product concept development, Computers in Industry 49(2), pp. 157-174.

Lee (1993), A structured methodology for software development effort prediction using the analytic hierarchy process, Journal of Systems and Software 21(2), pp. 179186.

Leidner, D.E. and Elam, J.J. "Executive Information Systems: Their Impact on Executive Decision Making", Journal of Management Information Systems 10 1994.

Lin, W.T., Shao, B.B.M. "The relationship between user participation and systems success: a simultaneous approach", Information \& Management (37:6) 2000, pp. 283-295.

Lu, H.; Yu, H. and Lu, S.S.K. 2001. The effects of cognitive style and model type on DSS acceptance: An empirical study, European Journal of Operational Research 131(3), pp. 649-663.

Mardle, S., Pascoe, S. and Herrero, I., 2003. Management Objective Importance in Fisheries: An Evaluation Using the Analytic Hierarchy Process (AHP). Environmental Management (Forthcoming).

Markus, M.L. "Power, politics and MIS implementation", Communications of the ACM (26:6) 1983, pp. 430-444.

Martinsons, M.G. and Cheung C. "The impact of emerging practise on IS specialists: perceptions, attitudes and role changes in Hong Kong", Information \& Management (38:3) 2001, pp. 167-183.

Min, H. (1992), Selection of Software: the Analytic Hierarchy Process, International Journal of Physical Distribution \& Logistics Management 22(1), pp. 42-52. 
Cite as: Salmeron and Herrero (2005). An AHP-based methodology to rank critical success factors of Executive Information Systems. Computer Standards \& Interfaces, 28: 1-12.

doi:10.1016/j.csi.2004.09.002. http://www.sciencedirect.com/science/article/pii/S0920548904001060

Mitta, D.A. (1993). "An application of the Analytic Hierarchy Process: a Rank-Ordering of Computer Interfaces". Human Factors 35(1). pp. 141-157.

Moynihan, G.P. "An Executive Information System: Planning for Post-Implementation at NASA", Journal of Systems Management 44 1993, pp. 8-14.

Munro, M.C. and Wheeler, B.R. 1980. "Planning, critical success factors, and management's information requirement", MIS Quarterly 4(4), pp. 27-38.

Muralidhar K.; Santhanam, R. and Wilson, R.L. 1990. Using the analytic hierarchy process for information system project selection, Information \& Management 18(2), pp. 87-95

Nord, J.H., Nord, G.D. 1995. "Executive Information Systems: A study and comparative analysis", Information \& Management 29.

Paller, A. and Laska, R. The EIS Book, Dow Jones-Irwin, Home-wood, IL, 1990.

Poon, P. and Wagner, C. 2001. "Critical success factors revisited: success and failure cases of information systems for senior executives", Decision Support Systems (30:4), pp. 393-418.

Procaccino, JD.; Verner, J.M.; Overmyer, S.P. and Darter, M.E., "Case study: factors for early prediction of software development success", Information and software technology (44) 2002, pp. 53-62.

Rai, A. and Bajwa, D.S. "An empirical investigation into factors relating to the adoption of executive information systems: An analysis of EIS for collaborating and decision support", Decision Sciences (28:4) 1997.

Rainer Jr., R.K. and Watson, H.J. "The keys to Executive Information Systems success", Journal of management information systems (12:2) 1995, pp. 83-98.

Rockart, J.F. "Chief executives define their own data needs", Harvard Business Review (57) 1979.

Rockart, J.F. and DeLong, D.W. Executive Support Systems: The Emergence of Top Management Computer Use, Dow Jones-Irwin, Homewood, IL, 1998. 
Cite as: Salmeron and Herrero (2005). An AHP-based methodology to rank critical success factors of Executive Information Systems. Computer Standards \& Interfaces, 28: 1-12.

Rockart, J.F., Treacy, M.E. "The CEO goes on-line", Harvard Business Review (60:1) 1982, pp. 82-89.

Saaty, T. L. The analytic hierarchy process: Planning, priority setting, resource allocation. McGraw-Hill, NY, 1980.

Saaty, T. L. "A scaling method for Priorities in Hierarchical Structures", Journal of Mathematical Psychology (15:3) 1977, pp. 234-281.

Salmeron, J.L. "EIS evolution in large Spanish businesses". Information \& Management (40:1) 2002, pp. 41-50.

Sawyer, S., "Packaged software: implications of the differences from custom approaches to software development", European Journal of Information Systems 9 (1) 2000, pp. 47 - 58.

Schniederjans, M.J., and Wilson, R.L., "Using the analytic hierarchy process and goal programming for information system project selection", Information and Management (20) 1991, pp.333-342.

Shank, M.E.; Boynton, A.C. and Zmud, R.W. 1985. "Critical success factor analysis as a methodology for MIS planning", MIS Quarterly 9(2), pp. 121-129.

Slevin, D.P. and Pinto, J.K. "Balancing Strategy and Tactics in Project Implementation," Sloan Management Rev., Fall 1987, pp. 33-44.

Szajna, B. and Scamell, R.W., "The Effects of Information Systems User Expectations on their Performance and Perceptions", MIS Quarterly (17:4) 1993, pp. 493516.

Tackett, B.D. and Doren, B.V. 1998. Error-Free Software: A Software Success Story. IEEE Software, May-June, pp. 24-29.

Tang, H.L., Lee, S. and Yen, D.C. "An Investigation on Developing Web-based Executive Information Systems", Journal of Computer Information Systems 1998. 
Cite as: Salmeron and Herrero (2005). An AHP-based methodology to rank critical success factors of Executive Information Systems. Computer Standards \& Interfaces, 28: 1-12.

doi:10.1016/j.csi.2004.09.002. http://www.sciencedirect.com/science/article/pii/S0920548904001060

Vandenbosch, B. and Higgins, C. "Executive support systems and learning: A Model and Empirical Test", Journal of Management Information Systems (12) 1995.

Vandenbosch, B. and Huff, S.L. "Searching and Scanning: How Executives Obtain Information From Executive Information Systems", MIS Quarterly (21:1) 1997, pp. 81-107.

Volonino, L. and Watson, H. "The SBO method for guiding EIS development", Journal of Management Information Systems (7:3) 1990, pp. 27-39.

Volonino, L.; Watson, H.J. and Robinson, S. "Using EIS to respond to dynamic business conditions", Decision Support Systems (14:2) 1995, pp. 105-116.

Walstrom, K.A. and Wilson, R.L. "An examination of Executive Information Systems (EIS) users", Information \& Management (32) 1997.

Watson, H.J.; Houdeshel, G. and Rainer Jr., R.K. Building Executive Information Systems and other Decision Support Applications. John Wiley \& Sons, NY, 1997.

Watson, H.J.; O'Hara, M.T.; Harp, C.G. and Kelly, G.G. "Including soft information in EISs", Information Systems Management (3) 1996, pp. 66-77.

Yang, C. and Huang, J. 2000. "A decision model for IS outsourcing". International Journal of Information Management 20(3), pp. 225-239.

Yau, C. and T. Davis (1993), Using Analytic Hierarchy Process to Prioritize Auditing Tasks for large-scale Software Systems, Journal of Systems Management 44 (11), pp. 26-31.

Young, D. and Watson, H.J., "Determinates of EIS acceptance", Information \& Management (29:3) 1995, pp. 153-164.

Zahedi, F. (1985), "Database Management Systems evaluation and selection decisions". Decision Sciences 16(1), pp. 91-116

Zahedi, F. "The Analytic Hierarchy Process. A survey of the method and its applications", Interfaces (16:4) 1986, pp. 96-108. 